\title{
Is the whole greater than the sum of the parts? Self-rated health and transdisciplinarity
}

\author{
Martin Picard $^{1^{*}}$, Robert-Paul Juster ${ }^{2}$, Catherine M. Sabiston ${ }^{3}$ \\ ${ }^{1}$ Center for Mitochondrial and Epigenomic Medicine, Children's Hospital of Philadelphia and University of Pennsylvania, Philadel- \\ phia, USA; ${ }^{*}$ Corresponding Author: picardm@email.chop.edu \\ ${ }^{2}$ Department of Neurology \& Neurosurgery, McGill University \& Centre of Studies on Human Stress, Fernand-Seguin Institute Uni- \\ versitaire en Santé mentale de Montréal, Montreal, Canada \\ ${ }^{3}$ Department of Kinesiology, University of Toronto, Toronto, Canada
}

Received 5 September 2013; revised 17 October 2013; accepted 26 October 2013

Copyright (C) 2013 Martin Picard et al. This is an open access article distributed under the Creative Commons Attribution License, which permits unrestricted use, distribution, and reproduction in any medium, provided the original work is properly cited.

\begin{abstract}
Self-rated health (SRH)-a person's subjective evaluation of his general health-is a more valid and powerful predictor of morbidity and mortality than any other combination of objective and self-reported measures. However, current theoretical frameworks fail to explain this association. Here, we sought to investigate $\mathrm{SRH}$ in relation to health outcomes from a transdisciplinary perspective. Using a selective review of epidemiological, clinical and qualitative SRH literature, we analyzed the relationships between this global subjective self-perception of health (the whole) and its directly measurable constituents (the parts). Although SRH often predicts major health outcomes, its underpinnings vary from person to person. Factors influencing individual's health interact in complex ways evade reductionist methods assessing the parts, and may be best captured by global self-perceptions of health. The study of SRH from a transdisciplinary perspective exemplifies the notion that the whole is greater than the sum of its parts. Insight into individual's experience of "health", their association with physiological processes, and impact on the health/disease continuum may contribute to the development of individualized strategies for health care and promotion with aging. In particular, this should be most valuable for addressing non-communicable health conditions where cross-talk between health domains (biological, psychological, social, behavioral, spiritual) may significantly contribute to pathophysiology.
\end{abstract}

Keywords: Self-Rated Health; Self-Perception; Transdisciplinary; Systems; Theoretical Framework

\section{INTRODUCTION}

A major goal of both research and health care communities is to understand and promote individuals' health and well-being throughout the lifespan. Part of this challenge lies is discerning how body and mind operate together to influence disease susceptibility and clinical outcomes [1]. It is well established that in addition to biological, metabolic and genetic factors that constitute the foundation of biomedicine, psychological, social, behavioral and spiritual factors influence the susceptibility and rate at which individuals develop certain chronic diseases, age, and die [2-7]. Some of the physiological mechanisms linking health domains-e.g., how psychological stress influence physiological functions, and vice-versa - have been elucidated and involve the interplay of neuro-hormonal mediators on immune processes and other systems $[8,9]$. However, it is still unclear how the interaction of different factors shapes long-term health and well-being. To address this question, the need for inter- and transdisciplinary frameworks to design and conduct research is increasingly recognized [10]. Such frameworks will allow scientist-practitioners to delineate the inherent complexity of health and diseases, and ultimately provide more comprehensive solutions to modern health challenges.

Another realization that could enhance our ability to care for, and prevent chronic diseases is the discovery of mechanisms accounting for inter-individual variability in health outcomes. Clinically, as George Engel indicated in his call for a bio-psycho-social model of medicine in 1977 [11], it is the norm rather than the exception that patients with identical diagnosis and/or genetic vulner- 
abilities present with discordant symptoms and responsiveness to therapy. Over ten years ago, the origin of inter-individual variability in disease susceptibility was expected to emerge from sequencing the entire human genome [12]. Over a decade later, the search for individualized determinants of health using gnome-wide association studies (GWAS) has yielded relatively little insight into the source of inter-individual disease susceptibility. Yet more recent efforts have involved cataloguing the exposome-the measure of all exposures of an individual in a lifetime and how those exposures relate to health [13]. The overarching motivation for these and other approaches lies in the belief that integrating "omics” technologies (genomics, proteomics, metabolomics, epigenomics) will paint a sufficiently comprehensive picture of human health to provide additional insights into the sources of inter-individual health differences and opportunities for promoting health at the individual level.

An assumption implicit to both transdisciplinary initiatives and the combination of omics technologies is that more pertinent health information can be gained by interrogating the whole compared to its individual parts. So, is the whole greater than the sum of its parts? The validity of this presumption and the notion of emergence have been discussed elsewhere $[14,15]$. But to scientifically address such a question requires unique datasets, which include reliable measures of the whole and of its individual parts. Researchers and clinicians typically probe the health of patients using highly selective measurement tools (blood work, molecular assays, scans, questionnaires, structured/semi-structured interviews, etc.) targeting the biological, psycho-social, behavioral parts. In addition, for over 30 years now, researchers have collected data on general health (the whole) as assessed subjectively by the individual. This is termed self-rated health (SRH).

Results from a large number of population-based SRH mixed-methods studies offer strikingly consistent results supporting the notion that indeed, the whole is greater than the sum of its parts. SRH often cannot be statistically deduced nor inferred from its parts, yet it is reliably the strongest predictor of major health outcomes in longitudinal studies. Elucidating the relationship between SRH (the whole), its parts (which are the domains of study of different disciplines-behavioral medicine, psychology, biology, etc.), and future health outcomes may provide unique insights into the individualized determinants of health. In this paper, we review the major findings from SRH research, discuss its transdisciplinary implications, and present a hypothetical framework to further our understanding of the individualized health determinants with potential clinical applications.

\section{WHAT IS SELF-RATED HEALTH?}

SRH (also self-perceived or self-assessed health) is an individual's perception of her/his health in general that does not focus on specific physical or mental health symptoms. SRH is generally assessed with a single question whereby respondents answer using a 5-point Likert scale ranging from "excellent” to "poor" (Table 1). This and slight variations of this question have been used in population health surveys (i.e., Canadian Community Health Survey-CCHS; National Health and Nutrition Examination Survey-NHANES in the US; English Longitudinal Study of Aging-ELSA) and incorporated into various general quality of life measures such as the 36-item short form (SF-36) health survey [16-18].

$\mathrm{SRH}$ is defined as an individual's perceived global health status. SRH is a strong independent predictor of clinical outcomes such as cancer, cardiovascular disease, and mortality [19-25]. This independent association between SRH and mortality exists in well-functioning healthy adults [26], and also in chronically ill cardiovascular patients [27] and in palliative care cancer patients where terminal disease status could be expected be the most determinant cause of death [28]. Interestingly, morbidity and mortality in both healthy and chronically ill individuals can often be more accurately predicted by SRH than by any other combination of objective and subjective measures [22,28,29]. Despite growing evidence that $\mathrm{SRH}$ is a valid predictor of major clinical outcomes, it is still not clear why people who rate their health as "poor" at one point in time tend to develop diseases 10 - 20 years later in life and die prematurely compared to those who rate their health as "excellent", even when controlling for important health confounds that could be expected to mediate these long-term effects $[16,19]$. The reliable prediction of short- and long-term clinical outcomes by a single general, or "holistic" question, above and beyond biological and clinical factors, represents a powerful argument for the presumption discussed above; namely, that important and more accurate information about a person's health state may be obtained by interrogating the whole rather that scrutinizing the parts.

SRH has been linked to other health variables (for a review, see [16]). On average, compared to individuals who rate their health as "fair" or "poor", those who rate their health as "excellent" have lower levels of blood biomarkers associated with stress and inflammation

Table 1. Self-rated health as used in the medical outcome study (MOS) short form 36-item (SF-36) health survey [18].

\begin{tabular}{l}
\multicolumn{1}{c}{ In general, would you say your health is... } \\
\hline 1) Excellent? \\
2) Very good? \\
3) Good? \\
4) Fair? \\
5) Poor? \\
\hline
\end{tabular}


[21,30], are more physically active [31,32], report less depressive symptoms [33], experience more positive and less negative affect [34], report more social support and healthy behaviors $[35,36]$, and have higher actual and perceived socio-economic status [37-40]. Yet, despite the fact that SRH is often correlated to several health "parts", the variance in SRH is not explained by their combination and cannot be decomposed into a defined set of variables. This is especially true when comparing across individuals.

\section{WHAT DOES SRH MEASURE?}

In spite of robust associations between SRH, mortality and morbidity, there are several instances where SRH does not to correlate with disease-specific clinical and biological markers. For example, SRH was poorly correlated with disease stage in cancer [28], airflow limitation in lung disease [41], and left ventricular ejection fraction in chronic heart failure [27]. Moreover, patient's SRH and actual disease progression are often not reflected in typical physical assessments (e.g., biomarkers, scans results, physical disability scores) or in objective physician's ratings of patient's disease severity [42-46]. Although SRH tends to be associated with clinical outcomes and diagnoses in population-based studies, the evidence listed above concerning specific diseases suggests that an individual's SRH is not necessarily determined by the individual's knowledge of given diagnoses or illness state. Even when measured several years before the emergence of preclinical symptoms and diagnosis, SRH is still predictive of chronic diseases [25]. Therefore, contrary to certain expectations, the relationship between SRH, morbidity and mortality does not largely depend on established clinical or medical variables. This highlights the potential clinical value of assessing patients' perceptions of their health.

Since SRH is not always linked to clinical markers of disease and disability, it is difficult to identify the underpinnings of SRH. In an effort to do so, Kaplan and Baron-Epel [20] studied what information individuals used to inform their SRH and identified multiple distinct perspectives. When respondents were asked what they consider in their self-ratings, answers varied widely from physical symptoms and pain, to social interactions, medical diagnoses and history, level of function and individual autonomy, comparison with others, etc. [20]. Interestingly, some people judge themselves as healthy ("excellent" in the SRH scale) despite having serious physical illnesses and diagnosed medical conditions $[28,47,48]$. A recent population study in the United Kingdom showed that on average, poor SRH was more strongly correlated with vitality and physical function than with other SF-36 constructs (i.e., mental health, emotionality, social function) [48]. This suggests that the majority of individuals in this study may ascribe more relative importance to physical functioning when judging their SRH. However, the contribution of different factors to inform SRH differs from person to person, between men and women, young and old, cross-culturally, and shifts over time [20,49-51]. A one-size-fits-all account of SRH is therefore unlikely to be fruitful.

Since the formulation of the question used to assess SRH is non-leading, SRH does not ubiquitously measure any single construct for all individuals. While some might contend that this makes SRH elusive [52], it can be argued that it is precisely because SRH measures subjective individualized dimensions that it taps into a global health construct of "true health". As indicated by others $[16,19]$, these individualized dimensions function together in a synergistic way (rather than in a additive, or linear way) to impact health and well-being. For example, a comprehensive study of nearly 2500 community-dwelling elders found that while illness and functional status were major determinants of SRH, the effects of social, economic, and psychological factors were also variably important [53]. The whole is indeed greater than the sum of its parts. In accordance, this supports the hypothesis that SRH is a complex indicator of global or "holistic" health, and implies that deciphering its foundation requires a transdisciplinary perspective.

\section{SRH AND TRANSDISCIPLINARITY}

A particular approach to evaluate the association between SRH and health outcomes involves considering health as a unique and complex state whereby the person is not de facto reduced to the sum of constituent parts [14,54]. In this context, physical and biological parameters are integral parts of a larger system [3]. As depicted in Figure 1, health is conceptualized as a state of the person that emerges from among the dynamic interactions of interdependent domains. This "global health state" is best understood (or rather, experienced) by individuals themselves and not captured by assessment of the body or mind parts. SRH may represent the best available tool to capture this experience. In the same way that life unexpectedly emerges (i.e., as an emergent property) from the complex interactions of molecules within a cell, the individual's global health state is inherently a transdisciplinary concept that emerges from the interaction among disciplinary parts.

Transdisciplinarity is increasingly recognized as a scientific approach that synergistically integrates multiple aspects of a problem to create new forms of knowledge that ultimately fosters global solutions to remedy health problems [54-58]. The concept of transdisciplinarity [59] was initially coined by Jean Piaget in 1970. It then evolved as a bridge linking health and social sciences [60] with George Engel's biopsychosocial model 


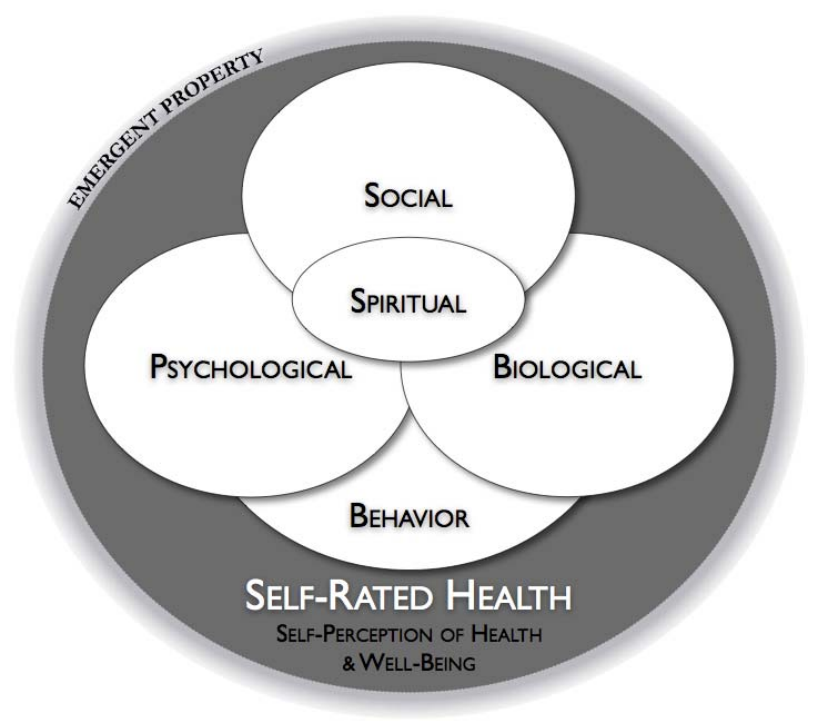

Figure 1. Global health as assessed by self-rated health (SRH) incorporates several health domains that dynamically and bi-directionally interact. For simplicity, five main domains are shown: biological/clinical, psychological, social, behavioral, and spiritual. The interaction among domains is illustrated by the overlap of the principal discipline-based domains. The respective size of each domain represents the relative influence typically ascribed to these domains, including the prominent bio-psycho-social triad, spirituality as a still poorly understood but central health domain, and finally behavior as the backdrop of other domains. The relative contribution of each domain to SRH may vary from person to person and over time. SRH is hypothesized to be an emergent property of the individual that arises from the complex interactions among the multiple components of a person's life. Figure adapted from [3].

emerging as one of its major predecessors [11,61]. Recently, transdisciplinary initiatives and training programs have been encouraged and sustained by national funding agencies [62-64] allowing innovative research perspectives to flourish (e.g., related to HIV/AIDS, public health, population chronic disease, psychosocial oncology). Health issues are complex scientific problems that benefit from transdisciplinary epistemological approaches [65].

Applying transdisciplinary thinking to SRH might reveal new ways of measuring health and to help intervene socially and clinically. Integrating multiple aspects of health into a unified concept has the potential to enhance our ability to conceive of sensitive clinical outcomes and to modulate the patient's global health experience $[3,14]$. In addition, understanding individual differences in the global health states/experiences may facilitate the development of social conceptions of health beyond "the absence of disease" towards more comprehensive approaches that promote positive health and resilience. The major challenge in this enterprise appears to be less about which aspects to include (amount of information), but rather about how to integrate them (synthesis of in- formation) [16] into meaningful, measurable variables that will be helpful to researchers and facilitate person/patient-centered strategies of research and care. The study of self-rated health might have something unique to teach us in this regard.

\section{CONCLUSIONS}

More than thirty years ago, it was proposed that "patients experience physical symptoms and dysfunctions in a more global manner than traditional medical conceptions would suggest that patients respond to their total sense of well-being” [66]. Long before, Hippocrates (460-377 B.C.) maintained that it is more important to know what sort of person has a disease than to know what sort of disease a person has. Based on mixed research evidence and observations from clinical practice, many have since argued for scientific perspectives conceiving health as a "global" phenomenon that emerges in ways whereby the whole is greater than the sum of its parts $[14,54,67]$. This argument is not about the primacy of "objective" or "subjective" outcomes, but about the integration of both into comprehensive transdisciplinary frameworks that more accurately represent the dynamics of health. SRH appears to tap into a domain of experience and knowledge that approaches a valid holistic evaluation of global health.

The accumulation of knowledge regarding SRH over the years has resulted in relatively few health-related social or economic gains. However, SRH can potentially provide powerful knowledge and tools to evaluate, understand and potentially intervene upon aspects of health. SRH has yielded challenging pieces of knowledge that health practitioners and researchers are struggling to fit into currently limited frameworks and theoretical models [16]. An individual who rates his/her health as "poor" in the absence of physical disease and psychiatric morbidity experiences something of major clinical and social relevance. The same can be said of subjective social status [68] and self-perceptions of aging [69], which also predict major health outcomes independent of objective measures. However, the physiological effects associated with self-perceptions of health, and the mechanisms linking SRH to mortality still evade the research and medical communities. Before SRH-inspired, simple and valid health assessments can be rigorously investigated and adopted by the general medical community, we will need to overcome the intellectual discomfort stemming from the lack of strong ties with tangible markers of physical health that are the current the benchmarks of Western medicine.

Understanding the interaction among complex aspects of human health requires new integrative frameworks that capture the individuality and complexity of health processes [14]. By appraising SRH from a transdiscipli- 
nary viewpoint, we might gain concrete insight about the underlying interconnections between self-perceptions of health and clinical outcomes, and between mind and body processes that influence the aging process. A transdisciplinary SRH-inspired paradigm offers an emergent lens to health care and promotion. This vision might be especially valuable to address chronic age-related, noncommunicable diseases where crosstalk between health domains is expected to significantly contribute to morbidity. In understanding individual health differences, this kind of framework may further assist in the transition from the one-size-fits-all model of health care towards a person-centered approach to behavioral medicine. Ultimately, health assessments and health-promoting interventions can only benefit from comprehensive holistic perspectives that capture individual differences in health and disease processes.

\section{ACKNOWLEDGEMENTS}

The authors are grateful to Yael Benyamini for providing useful comments and suggestions on an earlier version of this manuscript. Funding to the authors was provided by a Canadian Institute of Health Research (CIHR) Training Fellowships in Psychosocial Oncology and in Systems Biology, and a Postdoctoral Fellowship from the CIHR Institute of Neurosciences, Mental Health and Addiction as part of the Canadian Epigenetics, Environment and Health Research Consortium (CEEHRC) to MP; by a Fellowship from the CIHR Institute of Aging to RPJ; and by the Fonds de Recherche en Santé du Québec to CMS.

\section{REFERENCES}

[1] Brower, V. (2006) Mind-body research moves towards the mainstream. EMBO Reports, 7, 358-361. http://dx.doi.org/10.1038/sj.embor.7400671

[2] Carlson, L.E. and Bultz, B.D. (2008) Mind-body interventions in oncology. Current Treatment Options in Oncology, 9, 127-134. http://dx.doi.org/10.1007/s11864-008-0064-2

[3] Picard, M., Sabiston, C.M. and McNamara, J.K. (2011) The need for a trans-disciplinary, global health framework. Journal of Alternative and Complementary Medicine, 17, 179-184. http://dx.doi.org/10.1089/acm.2010.0149

[4] Vitetta, L., Anton, B., Cortizo, F. and Sali, A. (2005) Mind-body medicine: Stress and its impact on overall health and longevity. Annals of the New York Academy of Sciences, 1057, 492-505.

http://dx.doi.org/10.1196/annals.1322.038

[5] Fava, G.A. and Sonino, N. (2005) The clinical domains of psychosomatic medicine. Journal of Clinical Psychiatry, 66, 849-858. http://dx.doi.org/10.4088/JCP.v66n0707

[6] Cohen, S., Janicki-Deverts, D. and Miller, G.E. (2007) Psychological stress and disease. Journal of the American Medical Association, 298, 1685-1687. http://dx.doi.org/10.1001/jama.298.14.1685
[7] Picard, M. (2011) Pathways to aging: The mitochondrion at the intersection of biological and psychosocial sciences. Journal of Aging Research, 2011, Article ID: 814096. http://dx.doi.org/10.4061/2011/814096

[8] Taylor, A.G., Goehler, L.E., Galper, D.I., Innes, K.E. and Bourguignon, C. (2010) Top-down and bottom-up mechanisms in mind-body medicine: Development of an integrative framework for psychophysiological research. $E x$ plore New York, 6, 29-41.

[9] McEwen, B.S. (1998) Protective and damaging effects of stress mediators. The New England Journal of Medicine, 338, 171-179. http://dx.doi.org/10.1056/NEJM199801153380307

[10] Kessel, F., Rosenfield, P.L. and Anderson, N.B. (2008) Interdisciplinary research: Case studies from health and social science. Oxford University Press, New York. http://dx.doi.org/10.1093/acprof:oso/9780195324273.001 .0001

[11] Engel, G.L. (1977) The need for a new medical model: A challenge for biomedicine. Science, 196, 129-136. http://dx.doi.org/10.1126/science.847460

[12] Lander, E.S., Linton, L.M., Birren, B., Nusbaum, C., Zody, M.C., Baldwin, J., et al. (2001) Initial sequencing and analysis of the human genome. Nature, 409, 860-921. http://dx.doi.org/10.1038/35057062

[13] Center for Disease Control (2012) Exposomes and exposomics. http://www.cdc.gov/niosh/topics/exposome/

[14] Bell, I.R., Caspi, O., Schwartz, G.E., Grant, K.L., Gaudet, T.W., Rychener, D., et al. (2002) Integrative medicine and systemic outcomes research: Issues in the emergence of a new model for primary health care. Archives of Internal Medicine, 162, 133-140.

[15] Bell, I.R. and Koithan, M. (2006) Models for the study of whole systems. Integrative Cancer Therapies, 5, 293-307.

[16] Jylha, M. (2009) What is self-rated health and why does it predict mortality? Towards a unified conceptual model. Social Science \& Medicine, 69, 307-316.

[17] Statistics Canada (2009) Canadian community health survey.

http://wwwstatcangcca/cgi-bin/imdb/p2SVpl?Function= getSurvey\&SDDS=3226\&lang $=$ en $\& d b=i m d b \& a d m=8 \&$ $\underline{\text { dis }=2}$

[18] Ware Jr., J.E. and Sherbourne, CD. (1992) The MOS 36-item short-form health survey (SF-36). I. Conceptual framework and item selection. Medical Care, 30, 473-483. http://dx.doi.org/10.1097/00005650-199206000-00002

[19] Idler, E.L. and Benyamini, Y. (1997) Self-rated health and mortality: a review of twenty-seven community studies. Journal of Health and Social Behavior, 38, 21-37. http://dx.doi.org/10.2307/2955359

[20] Kaplan, G. and Baron-Epel, O. (2003) What lies behind the subjective evaluation of health status? Social Science \& Medicine, 56, 1669-1676. http://dx.doi.org/10.1001/jama.298.14.1685

[21] Jylha, M., Volpato, S. and Guralnik, J.M. (2006) Selfrated health showed a graded association with frequently used biomarkers in a large population sample. Journal of Clinical Epidemiology, 59, 465-471. 
http://dx.doi.org/10.1016/j.jclinepi.2005.12.004

[22] Mossey, J.M. and Shapiro, E. (1982) Self-rated health: A predictor of mortality among the elderly. American Journal of Public Health, 72, 800-808.

http://dx.doi.org/10.2105/AJPH.72.8.800

[23] Mason, C., Katzmarzyk, P.T., Craig, C.L. and Gauvin, L. (2007) Mortality and self-rated health in Canada. Journal of physical Activity \& Health, 4, 423-433.

[24] Nishi, A., Kawachi, I., Shirai, K., Hirai, H., Jeong, S. and Kondo, K. (2012) Sex/gender and socioeconomic differences in the predictive ability of self-rated health for mortality. PloS One, 7, Article ID: e30179.

http://dx.doi.org/10.1371/journal.pone.0030179

[25] Latham, K. and Peek, C.W. (2012) Self-rated health and morbidity onset among late midlife US adults. Journals of Gerontology Series B: Psychological Sciences and Social Sciences, 68, 107-116.

http://dx.doi.org/10.1093/geronb/gbs104

[26] Schoenfeld, D.E., Malmrose, L.C., Blazer, D.G., Gold, D.T. and Seeman, T.E. (1994) Self-rated health and mortality in the high-functioning elderly-A closer look at healthy individuals: MacArthur field study of successful aging. The Journals of Gerontology, 49, M109-M115. http://dx.doi.org/10.1093/geronj/49.3.M109

[27] Farkas, J., Nabb, S., Zaletel-Kragelj, L., Cleland, J.G. and Lainscak, M. (2009) Self-rated health and mortality in patients with chronic heart failure. European Journal of Heart Failure, 1, 518-524. http://dx.doi.org/10.1093/eurjhf/hfp038

[28] Shadbolt, B., Barresi, J. and Craft, P. (2002) Self-rated health as a predictor of survival among patients with advanced cancer. Journal of Clinical Oncology, 20, 25142519. http://dx.doi.org/10.1200/JCO.2002.08.060

[29] DeSalvo, K.B., Bloser, N., Reynolds, K., He, J. and Muntner, P. (2006) Mortality prediction with a single general self-rated health question. A meta-analysis. Journal of General Internal Medicine, 21, 267-275. http://dx.doi.org/10.1111/j.1525-1497.2005.00291.x

[30] Janszky, I., Lekander, M., Blom, M., Georgiades, A. and Ahnve, S. (2005) Self-rated health and vital exhaustion, but not depression, is related to inflammation in women with coronary heart disease. Brain, Behavior, and Immunity, 19, 555-563.

http://dx.doi.org/10.1016/j.bbi.2005.01.001

[31] Abu-Omar, K., Rutten, A. and Robine, J.M. (2004) Selfrated health and physical activity in the European Union. Soz Praventivmed, 49, 235-242. http://dx.doi.org/10.1007/s00038-004-3107-x

[32] Pan, S.Y., Cameron, C., Desmeules, M., Morrison, H., Craig, C.L. and Jiang, X. (2009) Individual, social, environmental, and physical environmental correlates with physical activity among Canadians: A cross-sectional study. BMC Public Health, 9, 21. http://dx.doi.org/10.1186/1471-2458-9-21

[33] Ruo, B., Bertenthal, D., Sen, S., Bittner, V., Ireland, C.C. and Hlatky, M.A. (2006) Self-rated health among women with coronary disease: Depression is as important as recent cardiovascular events. American Heart Journal, 152, 921, e1-e7. http://dx.doi.org/10.1016/j.ahj.2006.01.012
[34] Benyamini, Y., Idler, E.L., Leventhal, H. and Leventhal, E.A. (2000) Positive affect and function as influences on self-assessments of health: Expanding our view beyond illness and disability. Journals of Gerontology Series B: Psychological Sciences and Social Sciences, 55, P107P116. http://dx.doi.org/10.1093/geronb/55.2.P107

[35] Krause, N.M. and Jay, GM. (1994) What do global selfrated health items measure? Medical Care, 32, 930-942. http://dx.doi.org/10.1097/00005650-199409000-00004

[36] Harrington, J., Perry, I.J., Lutomski, J., Fitzgerald, A.P., Shiely, F., McGee, H., et al. (2009) Living longer and feeling better: Healthy lifestyle, self-rated health, obesity and depression in Ireland. European Journal of Public Health, 20, 91-95.

http://dx.doi.org/10.1093/eurpub/ckp102

[37] Demakakos, P., Nazroo, J., Breeze, E. and Marmot, M. (2008) Socioeconomic status and health: The role of subjective social status. Social Science \& Medicine, 67, 330340. http://dx.doi.org/10.1016/j.socscimed.2008.03.038

[38] Foraker, R.E., Rose, K.M., Chang, P.P., McNeill, A.M., Suchindran, C.M., Selvin, E., et al. (2011) Socioeconomic status and the trajectory of self-rated health. Age and Ageing, 40, 706-711. http://dx.doi.org/10.1093/ageing/afr069

[39] Goodman, E., Huang, B., Schafer-Kalkhoff, T. and Adler, N.E. (2007) Perceived socioeconomic status: A new type of identity that influences adolescents' self-rated health. The Journal of Adolescent Health, 41, 479-487. http://dx.doi.org/10.1016/j.jadohealth.2007.05.020

[40] Kondo, N., Sembajwe, G., Kawachi, I., van Dam, R.M., Subramanian, S.V. and Yamagata, Z. (2009) Income inequality, mortality, and self rated health: Meta-analysis of multilevel studies. British Medical Journal, 339, Article ID: b4471. http://dx.doi.org/10.1136/bmj.b4471

[41] Bendtsen, P., Leijon, M., Sofie Sommer, A. and Kristenson, M. (2003) Measuring health-related quality of life in patients with chronic obstructive pulmonary disease in a routine hospital setting: Feasibility and perceived value. Health and Quality of Life Outcomes, 1, 5. http://dx.doi.org/10.1186/1477-7525-1-5

[42] Litva, A. and Eyles, J. (1994) Health or healthy: Why people are not sick in a southern Ontarian town. Social Science \& Medicine, 39, 1083-1091. http://dx.doi.org/10.1016/0277-9536(94)90380-8

[43] Wilcox, V.L., Kasl, S.V. and Idler, E.L. (1996) Self-rated health and physical disability in elderly survivors of a major medical event. The Journals of Gerontology: Series $B, 51$, S96-S104. http://dx.doi.org/10.1093/geronb/51B.2.S96

[44] Kroenke, K., Wyrwich, K.W., Tierney, W.M., Babu, A.N. and Wolinsky, F.D. (2006) Physician-estimated disease severity in patients with chronic heart or lung disease: A cross-sectional analysis. Health and Quality of Life Outcomes, 4, 60. http://dx.doi.org/10.1186/1477-7525-4-60

[45] Ruo, B., Rumsfeld, J.S., Hlatky, M.A., Liu, H., Browner, W.S. and Whooley, M.A. (2003) Depressive symptoms and health-related quality of life: The heart and soul study. The Journal of the American Medical Association, 290, 215-221. http://dx.doi.org/10.1001/jama.290.2.215 
[46] Smith, K.V. and Goldman, N. (2011) Measuring health status: Self-, interviewer, and physician reports of overall health. Journal of Aging and Health, 23, 242-266. http://dx.doi.org/10.1177/0898264310383421

[47] Powers, B.A. (1988) Self-perceived health of elderly institutionalized people. Journal of Cross-Cultural Gerontology, 3, 299-321. http://dx.doi.org/10.1007/BF00116681

[48] Mavaddat, N., Kinmonth, A.L., Sanderson, S., Surtees, P., Bingham, S. and Khaw, K.T. (2010) What determines self-rated health (SRH)? A cross-sectional study of SF-36 health domains in the EPIC-Norfolk cohort. Journal of Epidemiology \& Community Health, 65, 800-806. http://dx.doi.org/jech.2009.090845v1

[49] Schwartz, C.E. and Finkelstein, J.A. (2009) Understanding inconsistencies in patient-reported outcomes after spine treatment: Response shift phenomena. The Spine Journal, 9, 1039-1045. http://dx.doi.org/10.1016/j.spinee.2009.05.010

[50] Hampson, S.E., Goldberg, L.R., Vogt, T.M., Hillier, T.A. and Dubanoski, J.P. (2009) Using physiological dysregulation to assess global health status: Associations with self-rated health and health behaviors. Journal of Health Psychology, 14, 232-241. http://dx.doi.org/10.1177/1359105308100207

[51] Galenkamp, H., Braam, A.W., Huisman, M. and Deeg, D.J. (2012) Seventeen-year time trend in poor self-rated health in older adults: Changing contributions of chronic diseases and disability. European Journal of Public Health, 23, 511-517. http://dx.doi.org/10.1093/eurpub/cks031

[52] Lang, T. and Delpierre, C. (2009) “How are you?”: What do you mean? European Journal of Public Health, 19, 353. http://dx.doi.org/10.1093/eurpub/ckp083

[53] Murata, C., Kondo, T., Tamakoshi, K., Yatsuya, H. and Toyoshima, H. (2006) Determinants of self-rated health: Could health status explain the association between self-rated health and mortality? Archives of Gerontology and Geriatrics, 43, 369-380. http://dx.doi.org/10.1016/j.archger.2006.01.002

[54] Albrecht, G., Freeman, S. and Higginbotham, N. (1998) Complexity and human health: The case for a transdisciplinary paradigm. Culture, Medicine and Psychiatry, 22, 55-92. http://dx.doi.org/10.1023/A:1005328821675

[55] Martin, C.M. (2003) Making a case for transdisciplinarity. Canadian Family Physician, 49, 905-908.

[56] Nicolescu, B. (2008) In vitro and In vivo knowledge: Methodology of transdisciplinarity. In: Nicolescu, B., Ed., Transdisciplinarity: Theory and Practice, Hampton Press, Cresskil.

[57] Choi, B.C. and Pak, A.W. (2006) Multidisciplinarity, interdisciplinarity and transdisciplinarity in health research, services, education and policy: 1 . Definitions, objectives, and evidence of effectiveness. Clinical \& Inves- tigative Medicine, 29, 351-364.

[58] Singer, B. and Ryff, C.D. (2001) New horizons in health: An integrative approach. By the committee on future directions for behavioral and social sciences research at the National Institutes of Health. National Academy Press, Washington DC.

[59] Freitas, L., Morin, E. and Nicolescu, B. (1994) Charter of transdisciplinarity. Adopted at the first World Congress of Trandisciplinarity. Convento da Arrábida, Portugal, 2-6 November 1994, 1.

[60] Rosenfield, P.L. (1992) The potential of transdisciplinary research for sustaining and extending linkages between the health and social sciences. Social Science \& Medicine, 35, 1343-1357. http://dx.doi.org/10.1016/0277-9536(92)90038-R

[61] Engel, G.L. (1980) The clinical application of the biopsychosocial model. American Journal of Psychiatry, 137, 535-544.

[62] Canadian Institutes of Health Research (2003) The future of public health in Canada: Developing a public health system for the 21st century. CIHR, Ottawa.

[63] Kessel, F. and Rosenfield, P.L. (2008) Toward transdisciplinary research: Historical and contemporary perspectives. American Journal of Preventive Medicine, 35, S225-S234.

http://dx.doi.org/10.1016/j.amepre.2008.05.005

[64] Loiselle, C.G., Bottorff, J.L., Butler, L. and Degner, L.F. (2004) PORT-Psychosocial oncology research training: A newly funded strategic initiative in health research. The Canadian Journal of Nursing Research, 36, 159-164.

[65] Knox, S.S. (2010) From 'omics' to complex disease: A systems biology approach to gene-environment interactions in cancer. Cancer Cell International, 10, 11. http://dx.doi.org/10.1186/1475-2867-10-11

[66] Tessler, R. and Mechanic, D. (1978) Psychological distress and perceived health status. Journal of Health and Social Behavior, 19, 254-262.

http://www.jstor.org/stable/2136558

[67] Federoff, H.J. and Gostin, L.O. (2009) Evolving from reductionism to holism: Is there a future for systems medicine? Journal of the American Medical Association, 302, 994-996. http://dx.doi.org/10.1001/jama.2009.1264

[68] Cundiff, J.M., Smith, T.W., Uchino, B.N. and Berg, C.A. (2013) Subjective social status: Construct validity and associations with psychosocial vulnerability and selfrated health. International Journal of Behavioral Medicine, 20, 148-158. http://dx.doi.org/10.1007/s12529-011-9206-1

[69] Levy, B.R., Slade, M.D., Kunkel, S.R. and Kasl, S.V. (2002) Longevity increased by positive self-perceptions of aging. Journal of Personality and Social Psychology, 83, 261-270. http://dx.doi.org/10.1037/0022-3514.83.2.261 